\title{
The Rights of non-Muslims in Islamic Law
}

\author{
Ahmad Dalbahi ${ }^{1}$ \\ ${ }^{1}$ APIUM University of Malaya \\ Email:ahmad_dahbahi@yahoo.com
}

\begin{abstract}
Constitutional law in Islam has been protecting the rights of all citizens of either Muslims or nonMuslims. in this study will be discussed several issues relating primarily to the rights of individuals in relation to the rights of citizens, especially Muslims as Muslims progress of individual rights, the right to obtain justice, honor guard in getting fair treatment from the state.
\end{abstract}

Keyword: Constitutional Law; Realting Primarily;Obtain Justice; Honor Guard;

إن القانون في المملكة في ضوء الشريعة الإسلامية كفلت حقوق الإنسان سواء كان مسلم أو غير مسلم مثل الوحدة الإنسانية والكرامة الإنسانية والعدل والوفاء والإحسان. حيس انني سوف أتطرق في مشاركتي إلى نبذه غختصرة عن الإسلام حيس انه دين كل زمان ومكان وان الإسلام كفل حق جميع من يعيش فيه حتى غير المسلمين مع العلم أنني سوف افصل في حقوق غير المسلمين في الشريعة الإسلامية مثل حق المساواة حق العدالة حق الحرية الشخصية حق الخرية الرأي والعقيدة حق حرية الإقامة والتنقل حق حرية الفكر والبحث العلمي حق سرية المراسلة. إن الإنسان من حيث هو إنسان، وضع مميز وواضح وفق قواعد الشريعة الإسلامية منذ نشأها، فقتد جاء

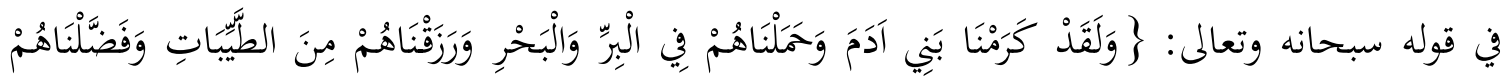

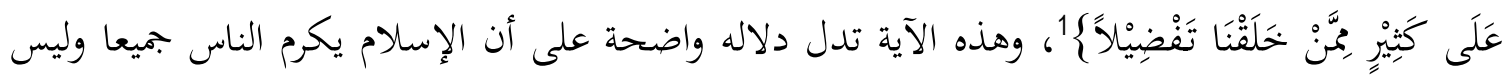

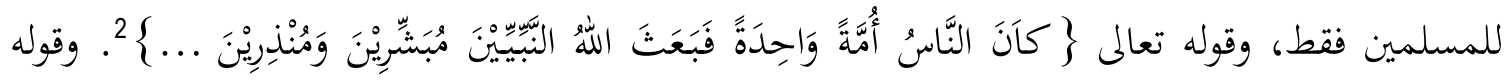

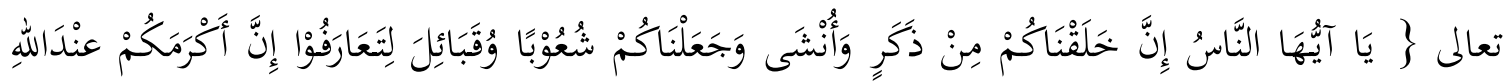

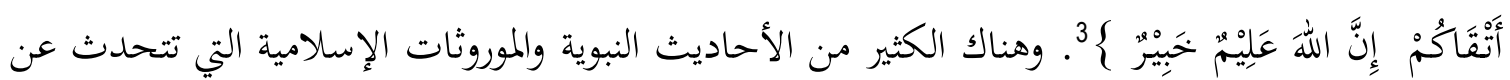
وحدة أصل البشرية كافة، وكرمة الإنسان. ليس هناك فضل العربي على عجمي ولالأحمر على أسود، وهذه هي الأسس والقواعد التي بنت عليها الشريعة الإسلامية. فقد جاء في ذلك: (... ليس لعربي على عجمي 
فضل إلا با التقوى ... وما من أمة من الأمم إلا وفيها الصالح و الطالح، والطيب والحبيث، والمقياس الوحيد بين الأمم إذن هو العمل الصالح ولا شيء سواه. ومن هنا فقد سمى هؤلاء الذين ينادون بأن الشعوب كلها سواء من حيث المبدأ، بأهل التسوية أو بالشعوبين)؛ ويرجع كل عمل يعمله الإنسان إلا نيته في العمل زهذا ما يؤكده قوله صلى الله عليه وسلم في حديث عمر بن الخطاب رضي الله عنه قال: إنما الأعمل بالنيات وإنما لكل امرئ مانوى فمن كانت هجرته إلى الله ورسوله فهجرته إلى الله ورسوله ومن كانت هجرته لدنيا يصيبها أو امرأة ينكحها فهجرته إلى ما هجر إليه) متفق عليه.

ان لغير المسلم أسس وحقوق محدده في إطار الشريعة الإسلامية، حيث ان الشريعة الإسلامية أوضحت بما

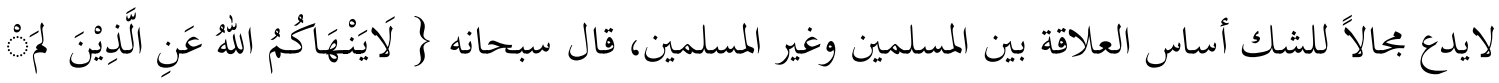

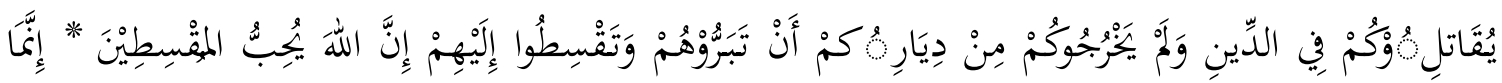

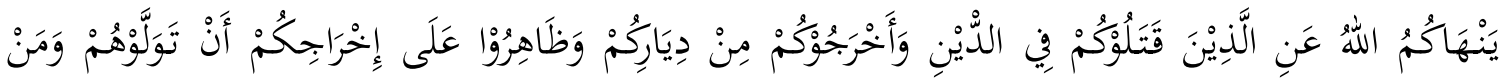

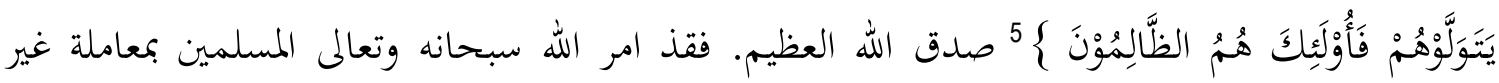
المسلمين بالبر والعدل وعدم التعدي على حقوقهم. وحفاظا على حقوق غير المسلمين فقدأقامت الشريعة الإسلامية سياجاً يحمي تلك الحقوق منذ نشأتما. وفي العصر الحديث اهتمت منظمة المؤتمر الإسلامي بحقوق غير المسلمين. وقد كان أول ظهور للإعلان الإسلامي لحقوق الإنسان في 19 سيتمبر عام 1981 م عندما أعلنت ذلك منظمة اليونسكو في الأمام المتحدة، وذلك بمبادرة من المحلس الإسلامي العالمي ، وأمينه العام/ السيد سالم عزامُ6.

أ ن إختلاف ألوان البشر وإختلاف ألسنتهم، ليست سوى أية من آياتة سبحانه وعتالى خالق الكون . وليس لهذه الإختلافات أثنر سلبي في وحدة الإنسانية. وقد جاء في ذلك قوله سبحانه وتعالى: \} وَمِنْ آيَاتِه

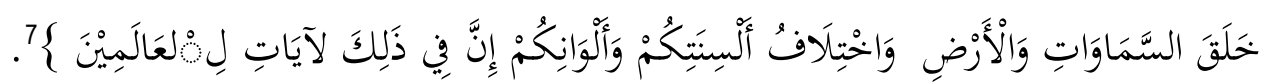

حيث أن التعاون يعتبر قيمة إنسانية لايمكن الإستغناء عنها، خاصة في ظل هذا العالم الجلديد، الذي التضح

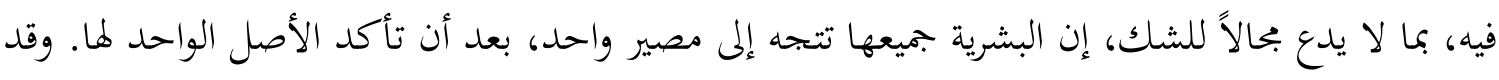
جاء تأكيدًا لذلك: ( يرتبط العالم المعاصر بالكرة الأرضية، أصل الحياة البشرية جميعًا، وقد أدى ذلك إلى لى

\footnotetext{
الثقافات الأجنبية في العصر العباس 132هـ / 334هـ وصداها في الأدب ـ دكثور / صالح ادم بيلو ـ الطبعة الأوله1408هـ 1988- مكة المكرمة

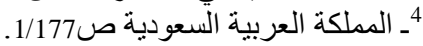
5

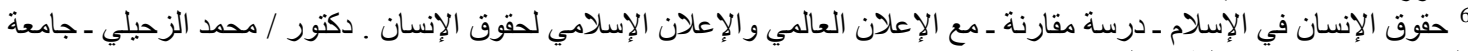

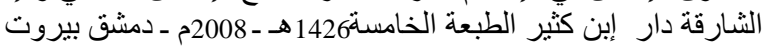

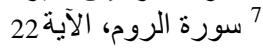


إحساس مشترك بوحدة المصير بين جميع دول العالم، وإلى الإحساس بالعالمية )8 وهذا ما يدفع إلى سبيل

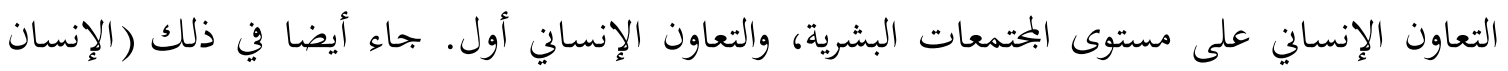
مدني بالطبع، أي لا يدله من الإجتماع، الذي هو (المدينة) وفي إصطلاح (الفقهاء) هو معن العمران.

الشريعة الإسلامية هي ليست ديانة فقط كبقية الديانة السماوية المعتبرة. بل هو دين ودولة، بمعنى إها

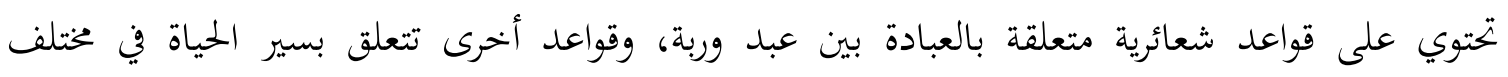

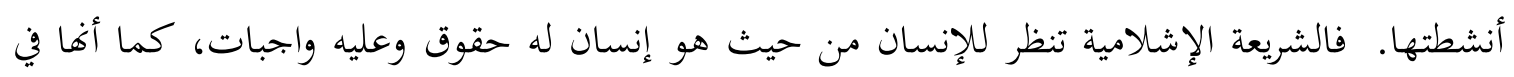

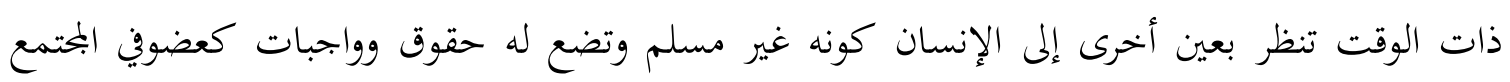

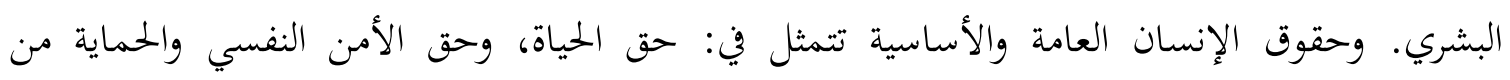

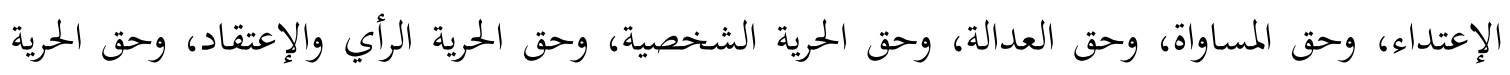

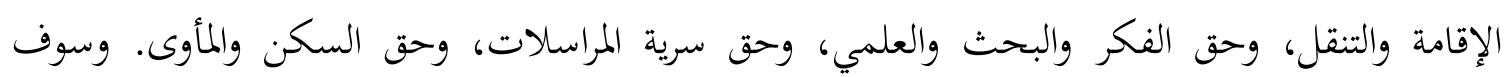
نتحدث في هذا الحقوق العامة والأساسية تباعًا في الشريعة الإسلامية.

الأول: حق الحيات

الحق في الحيات الحقوق العامة والأساسية في الشريعة الإسلامية فلا يحق لكائن من كان التعرض لحياة

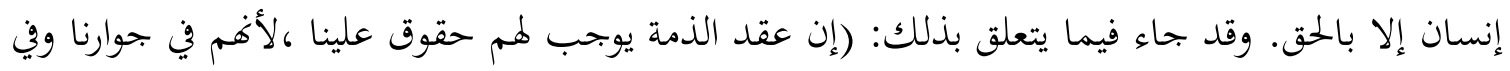

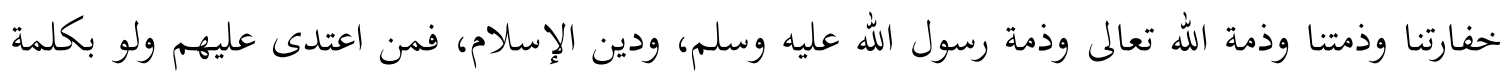

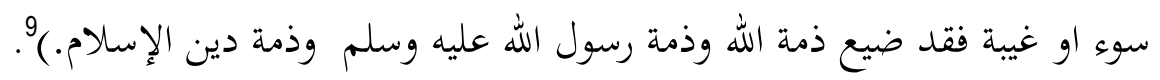

ولقد جاء أيضا فيما يتعلق بحماية دماء وأبدان أهل الذمة :(وحق الحمية المقرر لأهل الذمة يتضمن حماية

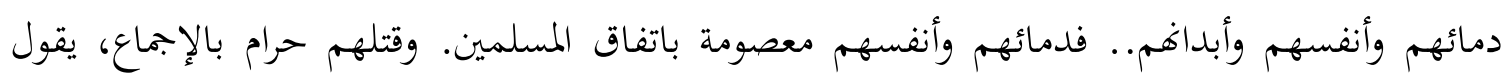

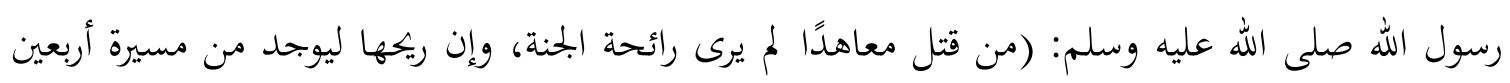

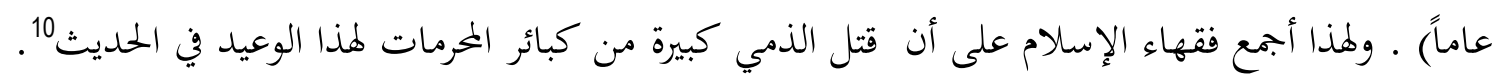

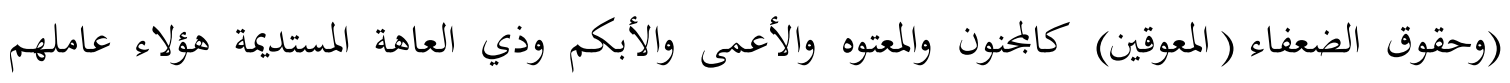

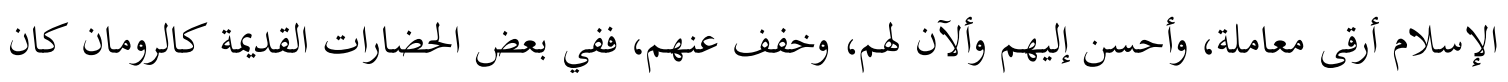

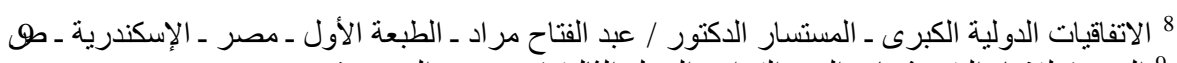

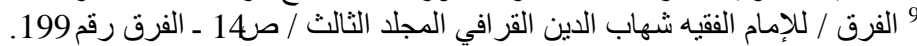

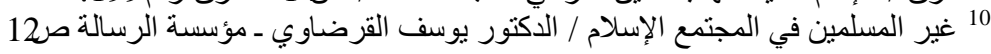


الأطفال الضعفاء يعرضون للمحنة الشديدة عند ولادتهم فإن الحياة عند الرومان للأقوياء فإن ما توا عند تعرضهم للمحنت كان ذلك خلاصاً منهم وان عاشوا أقوياء.)11.

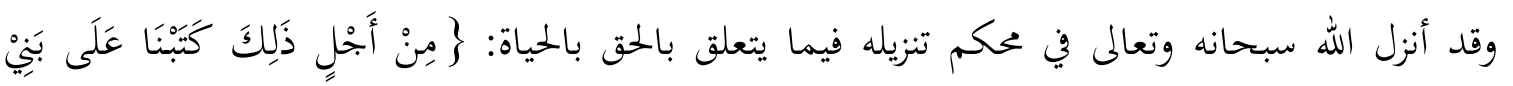

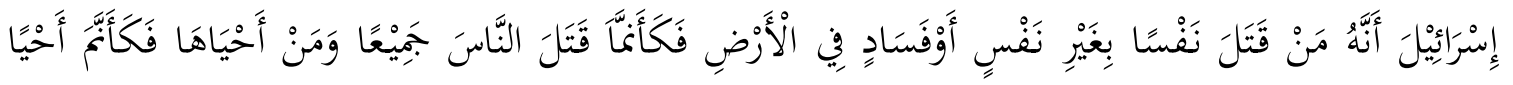

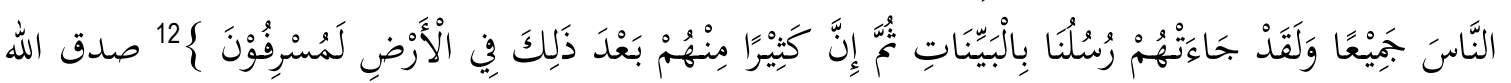
العظيم إن الحق في الحياة يعتبر من أهم الحقوق التي كفلتها الشريعة الإسلامية للإنسان فهذ الحق من نإِية منطقية هو الأسمى والأعلى من بقية الحقوق العامة اذ بفواته تفوت بقية الحقوق، الشيء الذي يتفق تماما مع التشريعيات الدولية والتي توصلت لما البشرية بعد جهد كبير عبر العصور المظلمة والى إن بلغة درجة من النضج الحضاري. ولذلك جاء الحق في الحياة في الاتفاقية الأوربية لحماية حقوق الإنسان في المادة الثانية

كما جاء الحق في الحياة في المادة الأولى للإعلان العالمي لحقوق الإنسان في الإسلام. وقد جاء تطبيقاً لذلك في الإتفقاية الأوربية: (حق كل إنسان في الحياة يحميه القانون ولا يجوز إعدام أي شخص عمدًا إلا تنفيذًا لحكم فضائي بإدانتهفي جريمة يقضي فيها القانون بتوقيع العقوبة.) وين الإعلان العالمي الحقوق الإنسان (حيات الإنسان مقدسة.. لا يجيوز الاعتداء عليها بأي حال. ولا تسلب هذه القدسية إلى بسلطان الشريعة وبالإجراءات التي تقرها)13. وعليه فان حق الحياة في الشريعة الإسلامية هو من الحقوق الأساسية التي عليها يقوم المحتمع البشري في الأرض.

\section{ثانياً: حق اللأمن النفسي والحماية من الاعتداء}

عرفنا في صدري هذا الفصل كلمة حق، وهنا نعرف كلمة نفس لغة: (النفس الروح يقال خرجة نفسه، والنفس الدم، يقال سالت نفس.

إن الأمن النفس هو امن الإنسان عينه لأن الإنسان عبارة عن جسد مادي ونفس أي بمعنى روح. والشريعة الإسلمية تحرم الإعتداء على نفس الإنسان أوبدونه، بمعنى تحرم الاعتداء المادي علي حقوق الإنسان المادية في عدم الاعتداءعلى جسده كما أغها تحرم عدم الاعتداء على نفسه أو روحه وذلك بالإهانه أو إساءة سمعته. أو كل ما يحز في النفس من قول أو فعل ، وقد انزل الله سبحانه وتعالى في محكم تنزيله آيات 


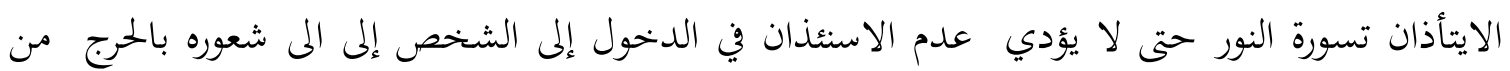

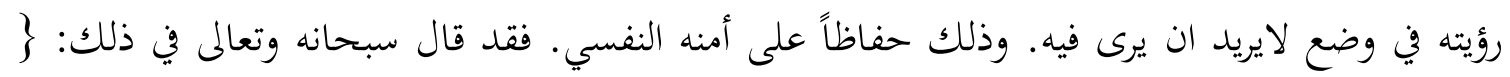

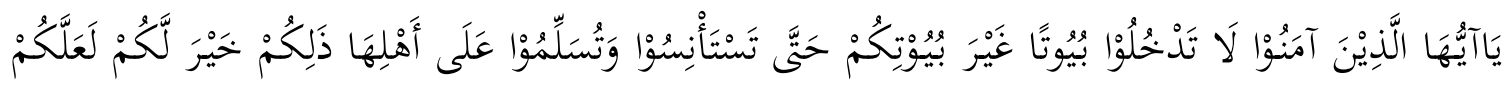
تَذَكَّرُوْنَ 14 وقوله سبحانه وتعالى

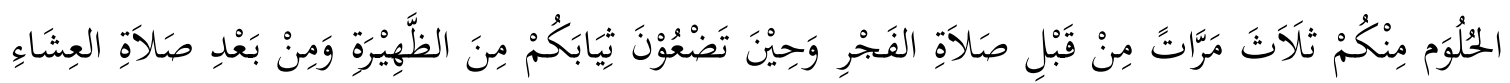

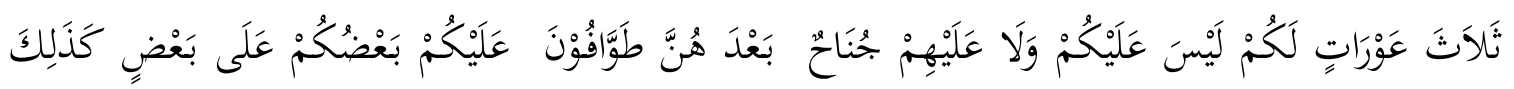

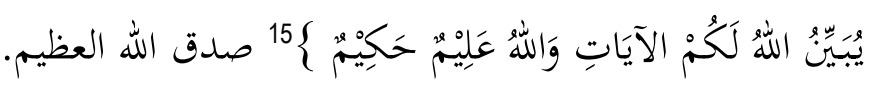

وقد جاء الأمن النفسي بوضوح في المادة الثالثة من الإعلان العالمي يحقوق الإنسان والتي تنص على الآتى:

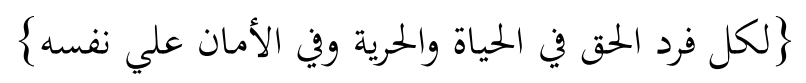

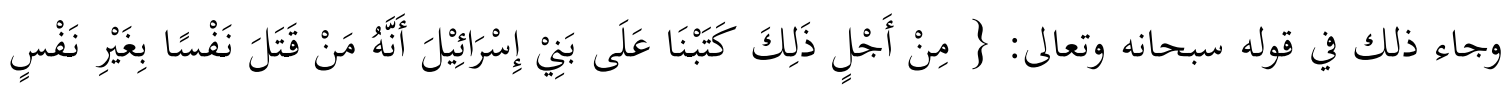

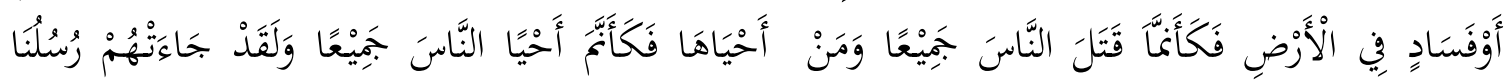

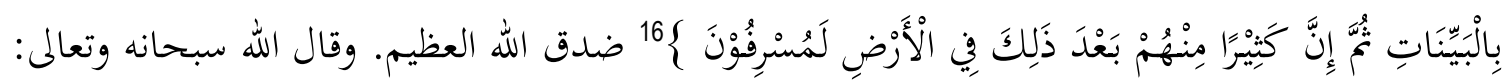

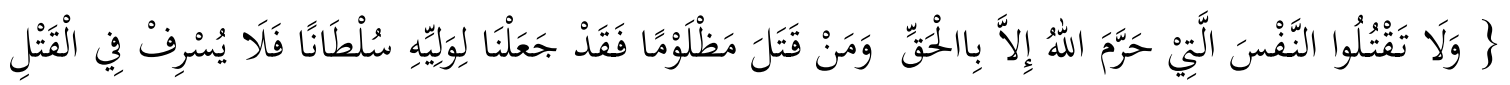

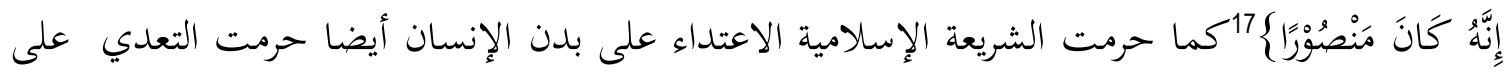

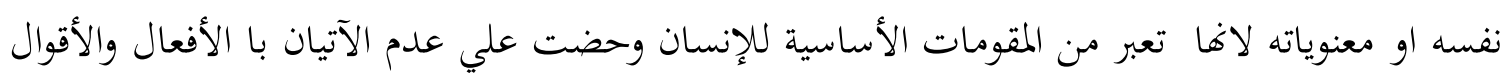

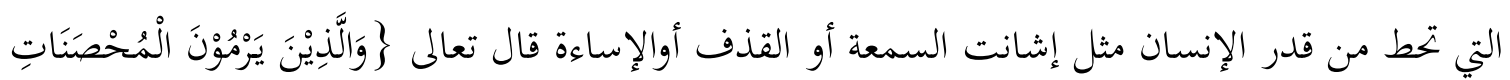

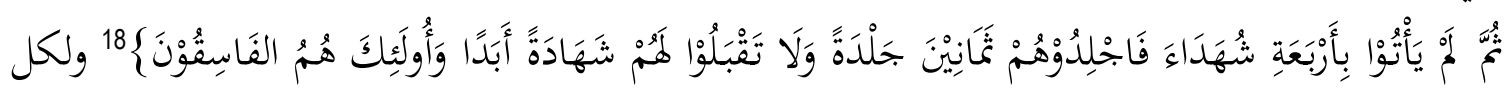

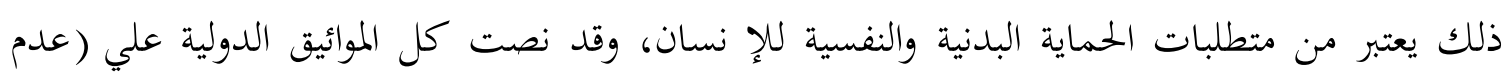

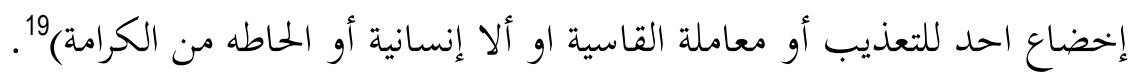


حق المساواة من الحقوق التي اهتمت بها الشريعة الإسلامية بصورة واضحة وجلية ـ فقد جاء في قوله

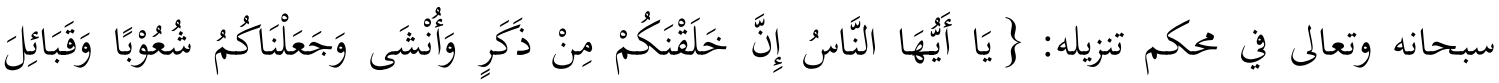

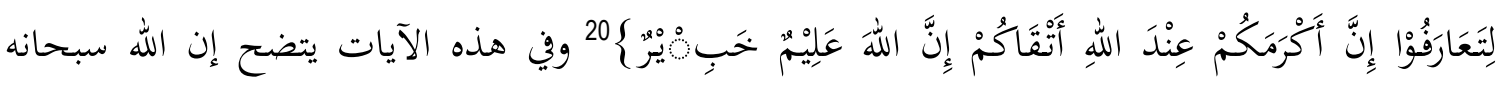

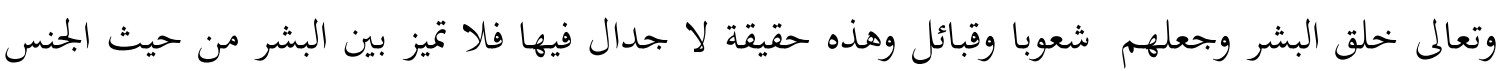
أو اللون أوالعرف، إنما وضع الله سبحانه وتعالى معيارًا محددًا لتحديد أكرم الناس، وهو التقوى أي مخافة الخالق سبحنه وتعلي وهو معيار العمل الصالح. وقد جاء في شرح هذه الآية: (لتعارفوا) حذف فيه احدي التاءين ليعرف بعضكم بعضاً لا لتفاخروا بعلو النسب. وإنما الفخر بالتقوى (إن أكرمكم عند الله اتقاكم) إن الله عليم بكم خبير ببواطنكم ل21.

فالحق بالمساواة يعتبر من الحقوق التي تحميها القوانين في غالبية المجتمعات البشرية إلا أن المساواة بين البشر في اعلي درجاقا لن بحدها إلا في القواعد المستمدة من الشريعة الإسلامية حيث إها منزله من عنده سبحانه وتعالي والخالق لاينظر إلي مخلوقاته إلا بعين واحدة بمعني أهم جميعا خلقه وقد جاء فيما يتعلق بالحق في المساواة: (يقوم مبدءا المساواة علي أساس النظرة الواحدة إلي الإفراد في الحقوق والواجبات بحيث تتبير المساواة بينهم هي الأساس للحقوق والحريات الفردية كون هذه المساواة تعد ألان احد عناصر حماية حقوق إلحرق الإنسان. وينظر إلي المساواة كوغا حقاً من حقوق الإنسان القانونية أو النظامية . فهس إذن مساواة قانونية أي رسمية ، وليست مساواة فعلية، بمعنى إن لكل فرد رسمياً الحق في التمتع لا الحقوق والحريات علي قدما المساواة مع الآخرين بغض النظر عن الإمكنيات المتاحة لكل منهم للتمتع فعلا بالحقوق والحريات، وتفسير ذلك: إن هناك تبايناً بين الإفراد في الإمكنيات والقدرات، ومن ثم وجد التفاوت الفعلي بينهم. وحينئ يكون هدف المساواة القانونية او النظامية هو إلغاء الامتيازات الطبيعية بين الأفراد، أما المساواة الفعلية، فوظيفتها التخفيف من الفوارق بين الأفراد من الناحية الاجتماعية).22.

رابعا: حقوق العدالة

العدالة إسم من عدل ( والعدل ضد الجمور او الظلم يقال عدل عليه القضية من باب ضرب فهو عادل.) وكلمة جور بمعنى (الميول عن القصد : تقول جار عن الطريق أي انحرف عنه، وجار عليه في الحكم أي أثقل

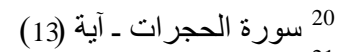
21 تفسير الجلالين ـ للإمامين الجليلين البين العلامة جلال الدين محمد بن احمد المحلي ـ و الثيخ المبتحر- جلال الدين عبد الرحمن بن بكر

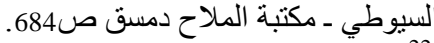
22 حقوق الإنسان في الإسلام وتطبيقاتها في الإنظمة السعودية ـ دكتو ناصر بن محمد البقمي مرجع سابق ـ صلإن

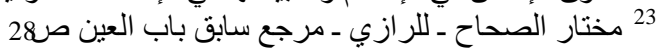


عليه )"24 بمعنى ظلمه. والظلم من المحرمات في الشريعة الإسلامية: قال تعالي في الحديث القدسي: (يا عبادي

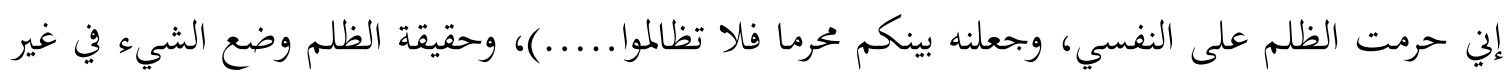

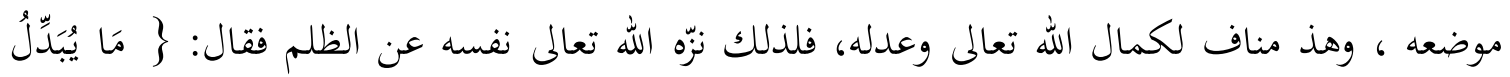

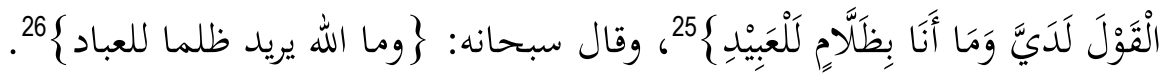

وقد جاء فيما يتعلق بذلك: (العدل المطلق هو العدل الإلهي الذي أرساه الله سبحانه وتعالى من خلال

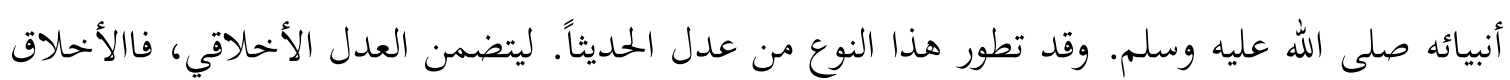
مؤسسة علي مبادئ الدين.

\section{خامساً: حق الحرية الشخصية}

إن كلمة حرية من الكلمات التي أعيت الفقهاء. فكم قامت حروب باسم الحرية والتحرر. والتاريخ القديم

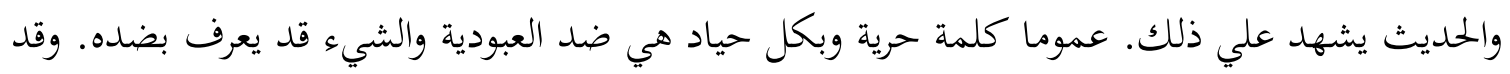

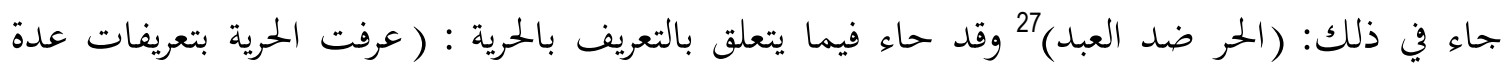

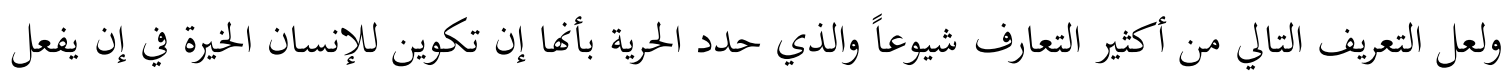

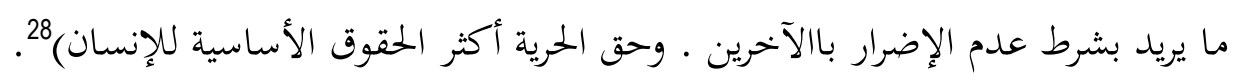

حيث أن العبد لا إرادة له فيما يفعل بخلاف الحر أي صاحب الإرادة، ومن منظور إسلامي فا الله سبحانه

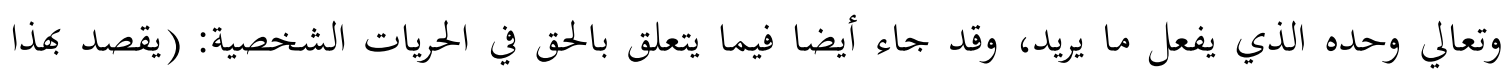

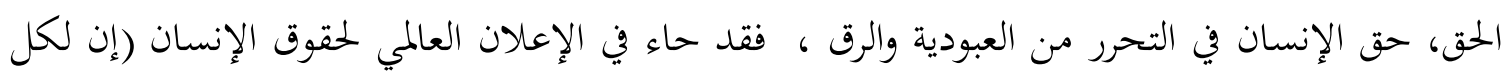

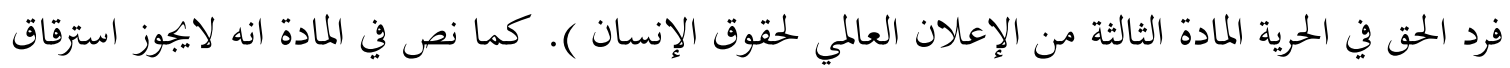

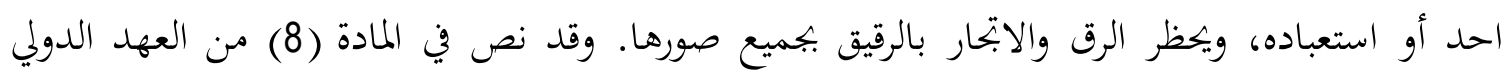

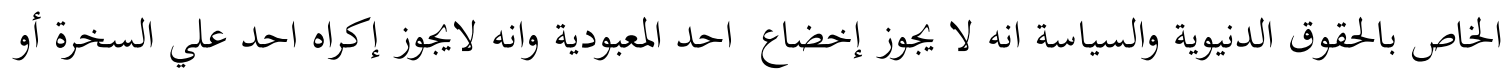

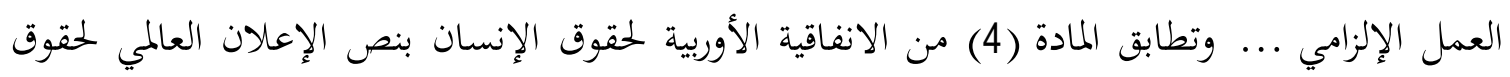
الإنسان ونصت المادة (6) من الانفاقية الأمريكية لحقوق الإنسان تحت عنوان تحريع الرق والعبودية. 
وجاء النص في المادة (2) من الإعلان العالمي لحقوق الإنسان في الإسلام تحت عنوان حق الحرية: (حرية الإنسان مقدسة. كحياته سواء ـ وهي الصفة الطبعية الأولي التي يولد بهاء الإنسان كما قل محمد صلى الله عليه وسلم (مامن مولد الا ويولد علي الفطرة ... ) وهي مستصحبة ومستمرة وليس الأحد إن يعتدي عليها وقد قال الخليفة عمر رضي الله عن (متى استعبدتم الناس وقد ولدقمم أمهاتم أحرارا)

\section{سادساً: حق الحرية الرأي والعقيدة}

حرية الرأي والعقيدة من الحقوق المكفولة لغير المسلمين وهي من ناحية منطقية لا يمكن إجبار أي شخص علي الإيمان بمعتقد معين. فالإيمان والاعتقاد محله القلب ولا سلطان لأحد علي ذلك. ولا ولا إكراه في الدين

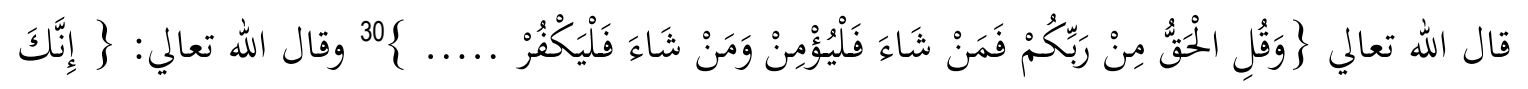

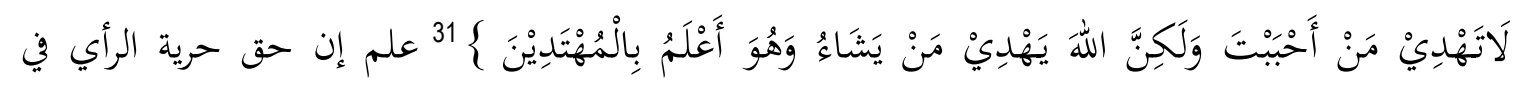
الشريعة الإسلامية أيضا ليس على إطلاقها، وركن الله سبحانه وتعالي جعل للبشر عقلاً يفكرون به ويميزون به الخير من الشر. والآيات التي تبين مكانة العقل كثيرة في القرآن الكريع. وقد جاء فيما يتعلق بوظيفة العقل ( ان حرية الفكر كما اقرها الإسلام مستمدة من واجبة التبصر والتدبر وصفاء البصيرة الذي هو من صلب كرامة الإنسان لذلك بحد الكثير من آيات القرآن الكريم تحض الناس على استحدام العقل وتحرير الفكر في كل ما تقع عليه أبصارهم زما تسمعه أذاهم، ليصلوا من وراء ذلك إلى معرفة الخالق. وليستطيعوا أن يميزوا بين الحق

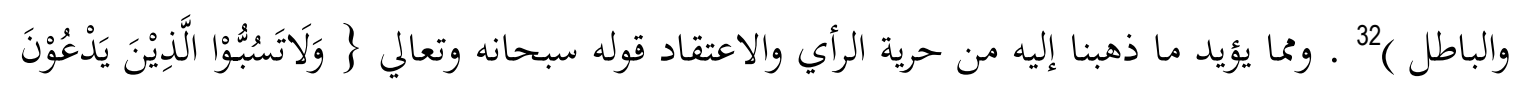

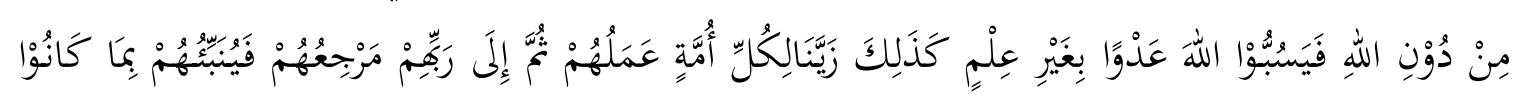

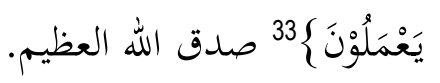

\section{سابعا: حق حرية الفكر والبحث العلمي}

ان حق الفكر والبحث العلمي يعتبر من حقوق الأساسية الطبيعية التي تتفق وخلق الإنسان وماله من مقدرات فكرية وعملية وعلمية الشيء الذي تقره الشريعة الإسلامية. سوف نسلط الكثير من الضوء خاصة عند مقارنة هذه الحقوق المستمدة من الشريعة الإسلامية علما ان هناك تطابق في بعض القواعد والحقوق

29 حقوق الإنسان في الججال الحياتي دراسة ـ مقارنة ـ دكتور عوض الحسن النور ـ الطبعة الأوليو199 ـ السودان ـ الجهاز القضائي ـص

$$
\begin{aligned}
& 30 \text { سورة الكهف ـ آية (29) } \\
& 31 \text { سورة القصص ـ آية } 56 \\
& 32 \text { سقوق الإنسان في الإسلام ـ مرجع سابق ص163 ألئس } \\
& 33 \text { سورة الأنعام - أية (108) }
\end{aligned}
$$


والحرياتالعامة الواردة بالمعاهدات والاتفاقيات الدولية مع القواعد والحقوق والحريات المستمدة من الشريعة الإسلامية إن

وكما سبق وان ذكرنا ان قمة الفكر الإنساني الذي يعتز به الكثير من العلمانيون، لايمثل إلا بداية للشريعة الإسلامية التي لم تمربمرحلة تطور كماهوالحال في الفكر الإنساني ولم يتم التوصل إلى تلك الحقوق والحريات نتيجة لتجرية إنسانية مادية، إنما هو وحى من عنده سبحانه وتعالى وهو خالق البشر جميعاً وهو وحده يعلم ما ينفع الناس وما يضرهم لذلك أرسل إليهم الرسل ليبينوا للناس الطريق القوم. وكان صلى الله عليه وسلم

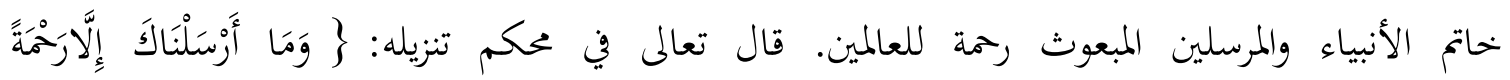

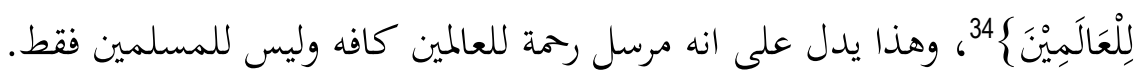

وإذسلمنا أن الشريعة الإسلامية من عنده سبحانه وتعالى خالق البشر أجمعين فلا بحال للعوامل المؤثرة على تلك الحقوق والحريات من مصالح ذاتية ضيقة. ولا نحياز الأي جهة كانت ولا تمييزبين البشر عند تنزيل تلك الحقوق والحريات ليحز التطبيق، إذ انه سبحانه وتعالى منزه عن كل تلك النقائص. كما نضيف بأن المحتمع المسلم حين يتعامل مع هذه الحقوق والحريات فهي بمثابة واجب قبل إن تكون حقاً، وفلسفته في ذلك ابتغاء مرضاة الله. وحسن ثوابه في الدار الآخرة وليس لغرض من أغراض الدنيا الفانية.

\section{ثامنا: حق سريعة المراسلات}

حق سرية المرسلات من الحقوق التي بند أها أرست الكثير من المبادئ والقواعد التي تنهي عن انتهاك خصوصية الفرد مسلما كان ام غير مسلم. ومما يميز الشريعة الإسلامية أها تضع مبدأ عاماً او قاعدة كلية بحيث يندرج تحتها الكثيرمن القواعد التفصيلية التي تنطبق عليها شروط المبدأ العام ومثال ذلك ما انزله الحق

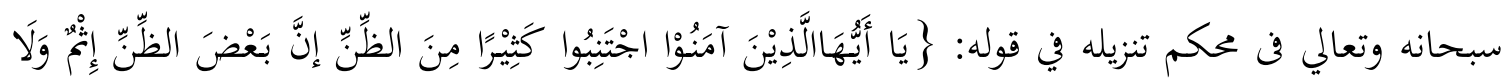

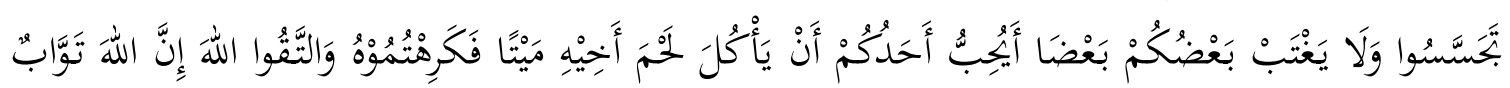
رَحِيهُ \{35. محا ذكرنا من آيات قرآنية وأحاديث فإها تدل بصورة مباشرة علي عدم انتهاك خصوصية الفرد أيا كان نوع هذا انتهاك، وعن طريق القياس يندرج الحق سرية المراسلات، فليس لأحد الحق في الاطلاع عليها دون إذن من صاحبها او وفق الشروط الشريعة المستمدة أيضامن الشريعة الإسلامية . 
ان حق السكن والمأوي يعتبر من ضمن الحقوق الطبيعية للإنسان، وهي من الحقوق التي تدعم الحق

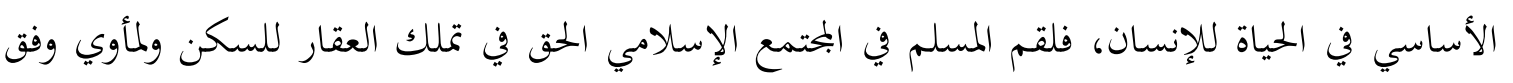

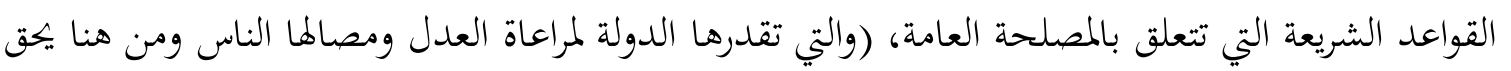

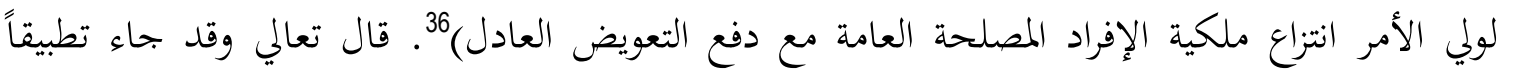

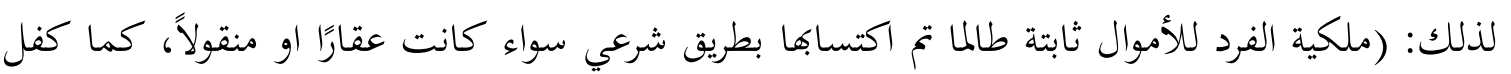

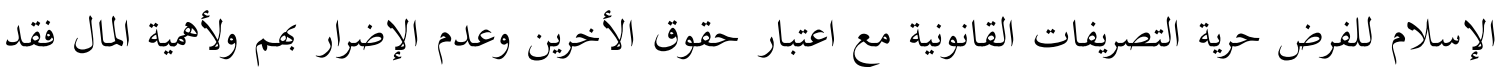

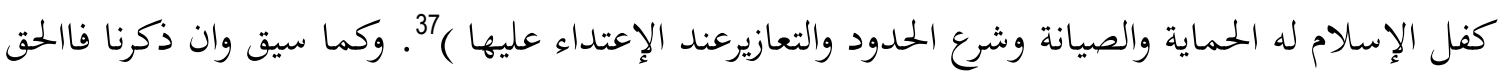

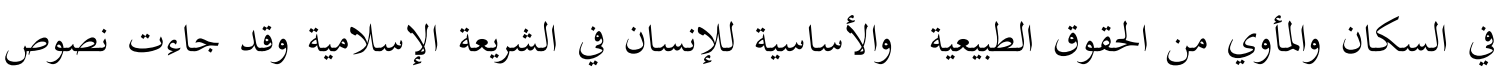

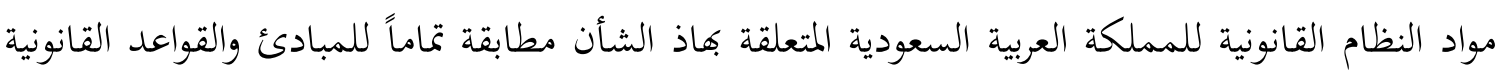
الشرعية، وقد جاء تطبيقاً لذلك في المادة السابعة عشر من النطام الأساسي للحكم بالمملكة العربية السعودية ( الملكية ورأس المال والعمل مقومات أساسية في الكيان الاقتصادي والاجتماعي للمملكة.

وهي حقوق خاصة تؤدي وظيفة اجتماعية وفق الشريعة الإسلامية ). وقد جاء أيضاء في المادة الثامنة عشرة

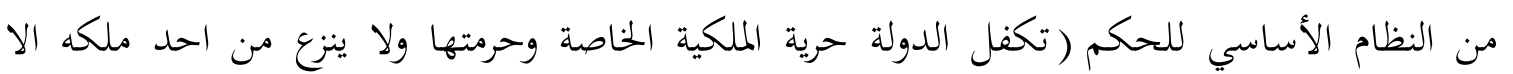

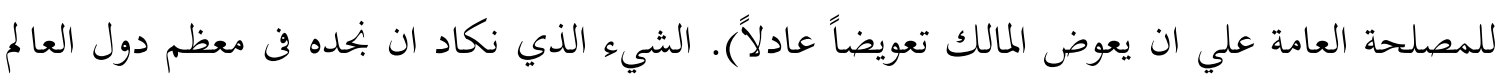

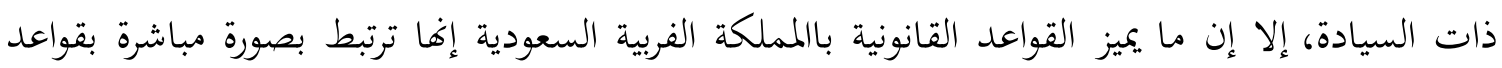
الدين وان الحرص علي تطبيق مثل هذه القواعد يراعي فيه حق الإفراد الذي منحة لهم الله سبحانه وتعالي.

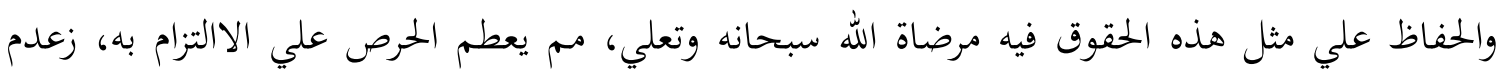

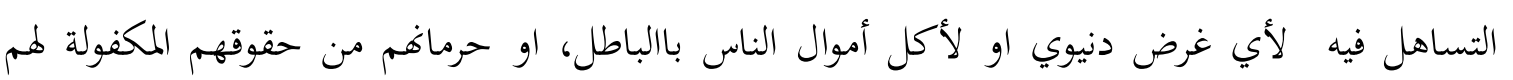

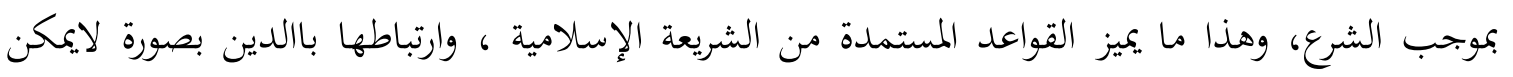

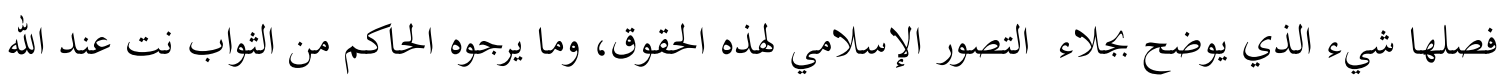

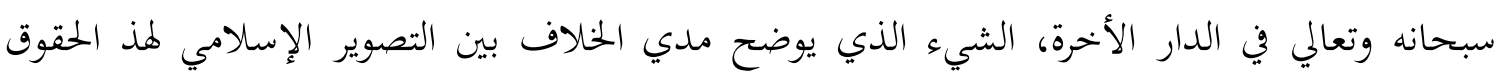

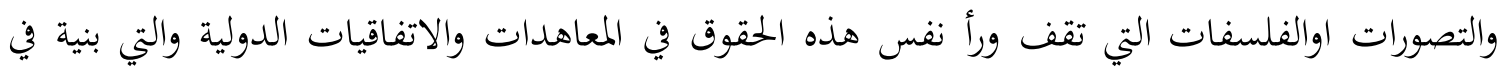

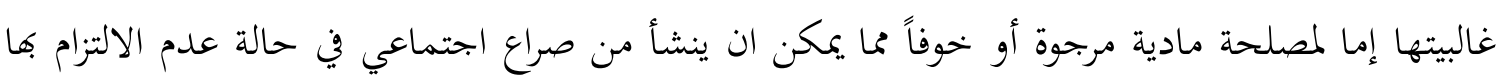

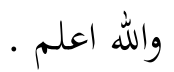




\section{المصادر والمراجع}

تفسير الجلالين. للإمامين الجليلين العلامة جلال الدين محمد بن احمد المحلي. والشيخ جلال الدين عبد

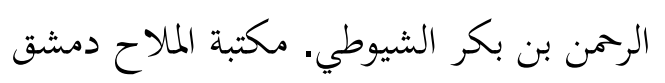

الثقافات الأجنبية في العصر العباسي 132هـ / 334هـ وصداها في الأدب. دكتور / صالح آدم بيلو. الطبعة الأول 1408هـ 1988. مكة المكرمة ـ المملكة العربية السعودية.

حقوق الإنسان في الإسلام. دراسة مقارنة. مع الإعلان العالمي والإعلان الإسلامي لحقوق الإنسان. دكتور / محمد الزحيلي. جامعة الشرقة درقة إبن كثير. الطبعة الخامسة 1426هـ ـ 2008 م. دمشق بيروت.

الاتفاقيات الدولية الكبرى. المستشار الدكتور / عبد الفتاح مراد. الطبعة الأول. الإسكندرية. مصر. الفروق / للإمام الفقيه شهاب الدين القرافي البحلد الثالث. الفرق رقم 119. غير المسلمين في البحتمع الإسلام / الدكتور يوسف القرضاوي. مؤسسة الرسالة. 2001 ـ بيروت لبنان حقوق الإنسان في الإسلام. دكتور أبرهيم المرزوقي. المجمع الثقافي 1977. أبو ظبي الآمزات حقوق الإنسان فن الإسلام. وتطبيقاها في الأظمة السعودية. دكتور / ناصر بن محمد البقمي. الطبعة الثانية 2009

حقوق الإنسان في المحال الحياتي دراسة. مقارنة. دكتور عوض الحسن النور. الطبعة الأولي 1999. السودان غير المسلمين في المختمع الإسلامي / الدكتور يوسف القرضاوي. مؤسسة الرسالةص 12. 